\title{
Development and evaluation of STAR - an expert digital platform supporting training and delivery of cessation interventions by healthcare professionals in Poland. Project overview
}

\author{
Aleksandra Herbeć ${ }^{1,2}$, Kinga Janik-Koncewicz ${ }^{1}$, Andy McEwen ${ }^{3}$, Robert West ${ }^{2}$, Witold A. Zatoński ${ }^{1,4}$ \\ ${ }^{1}$ Health Promotion Foundation, Nadarzyn, Poland \\ 2University College London, UK \\ ${ }^{3}$ National Centre for Smoking Cessation and Training, UK \\ ${ }^{4}$ Medical University, Wrocław, Poland
}

\begin{abstract}
Access to smoking cessation treatment, and in particular to dedicated stop smoking services, is limited in many countries. Digital tools could support healthcare professionals (HCPs) with limited training and resources to deliver evidence-based cessation treatment to their patients. The presented project aims to develop, evaluate and disseminate the STAR (Smoking Treatment Advisory Resource) Programme a novel internet-based platform acting as a support tool and expert system for data gathering, delivery of evidence-based treatment, networking, and training for HCPs offering cessation treatment. This will be accomplished through three phases. Phase 1 will be devoted to development of STAR, including formative research, expert consultations and interviews with HCPs and patients who smoke. Phase 2 will involve mixed-methods evaluation of STAR. Finally, during Phase 3 the STAR Programme will be refined and promoted among a wider community of HCPs and patients, and the results disseminated. STAR will be evaluated using mixed-methods, including quantitative assessments of changes in key indicators from baseline to immediate post-training and follow-up; as well as qualitative evaluation. It is expected that the project will result in the development of an acceptable and sustainable Programme that will increase the number of HCPs delivering evidence-based cessation support.
\end{abstract}

KEY WORDS: smoking cessation, healthcare professional training, support in tobacco depedence treatment, digital tool.

ADDRESS FOR CORRESPONDENCE: Aleksandra Herbeć, Department of Behavioural Science and Health,

University College London, 1-19 Torrington Place, London, UK, e-mail: aaherbec@gmail.com

\section{INTRODUCTION}

The World Health Organization Framework Convention on Tobacco Control (FCTC) outlines key measures and actions that should be implemented to advance tobacco control and limit the mortality and morbidity due to tobacco use [1]. Article 14 of FCTC emphasises the importance of offering support with treatment of tobacco dependence as a measure which can bring significant public health gains $[1,2]$.
The most effective cessation interventions should involve appropriate pharmacotherapy and behavioural support $[3,4]$. A range of medications have been licenced as cessation aids in different countries, including cytisine [5-7] varenicline [8], bupropion, as well as nicotine replacement therapy $[9,10]$, and these can improve cessation 2-3 fold [11]. With regards to behavioural support, the recommended interventions include: intensive group and individual support delivered by trained cessa- 
tion specialists, quitlines, brief advice, or self-help interventions. Behavioural support is effective, and should be offered to all smokers interested in quitting $[12,13]$. Brief advice from healthcare professionals, involving identification and assessment of smoking, as well as advice to use evidence-based support or referrals to dedicated available cessation support, has been shown to be cost-effective and instrumental at improving cessation efforts on population level $[14,15]$.

However, access to dedicated smoking cessation treatment for smokers is still limited in many countries [16], and even when it is made available free at the point of access (e.g. in the UK), few smokers access it $[17,18]$. Furthermore, access to appropriate training in smoking cessation tends to be limited as well, and many healthcare professionals report a range of barriers to offering cessation support [19-22].

\section{TOBACCO CONTROL AND TREATMENT}

\section{OF TOBACCO DEPENDENCE IN POLAND}

Over the past three decades Poland has made tremendous advances in tobacco control, strengthened by the implementation of the milestone Tobacco Control Bill in 1995 as well in building capacity for treatment of tobacco dependence [23]. Tobacco consumption in Poland has been gradually falling since 1980s, from the peak of $62 \%$ among men and 30\% among women in 1982. Nevertheless, a considerable proportion of adults still smokes daily in Poland (around 8 million Poles; $28 \%$ of males, and 19\% of females), with more than half interested in quitting and having tried to quit in the past $[24,25]$.

Crucially, contrary to best clinical practice and Article 14 FCTC guidelines, smoking cessation is not routinely offered to patients who smoke, and access to cessation clinics and behavioural support is limited. This is despite it being encouraged by the Consensus on Diagnosis and Treatment of Tobacco Dependence developed for Poland [26]. For example, only eight stop smoking clinics were listed as operating in Poland in 2016 (data from the Polish National Quitline Service, March 2016, jakrzucicpalenie.pl/poradnie/). According to statistics on cessation support that is reimbursed by the national health system in Poland, in 2014 just over nine thousand smokers in Poland were assessed for smoking status and offered advice to quit $(<1 \%$ of the smoking population), and fewer than 2500 smokers accessed dedicated stop smoking support services, which in case of some voivodeships (regions) was fewer than 40 smokers [27]. Although this is likely an underestimation of all smokers accessing cessation support in Poland, the figure is much lower than the number of smokers who access cessation services than in the UK (almost 590000 in the same time period), a country with a similar number of smokers to Poland [28]. Furthermore, training on tobacco dependence treatment is not part of the curriculum in most medical schools. Therefore, the capability and competen- cies to offer evidence-based treatment, particularly provision of behavioural support by HCPs remains limited in Poland. All of these result in limited access of patients who smoke to appropriate cessation support and advice.

\section{DIGITAL TOOLS SUPPORTING CESSATION TREATMENT}

Digital interventions and programmes are becoming increasingly popular in a range of healthcare settings, from clinical decision aids [29-33], to remote patient monitoring [34, 35], as well as standalone behaviour change interventions [36]. Important advances have also been made in creating acceptable and cost-effective interventions supporting smoking cessation [37, 38], particularly involving web-based [39-41] and mobilebased (e.g. SMS texting) [42, 43] interventions. Although such tools are not expected to replace or offer a comparable level of support to traditional face-to-face interventions, they could nonetheless act as valuable cessation aids for smokers who are unable or unwilling to access other programmes $[37,44]$. Moreover, even though their effectiveness is relatively low, when offered on a population level they could have important clinical impact and improve cessation efforts and success [45].

Digital tools could also support healthcare professionals (HCPs) who have limited training and resources to deliver evidence-based cessation treatment to patients. The concept of hybrid interventions, where digital tools support clinicians and advisors, are seen as the future of smoking cessation [37]. Such tools could help to address many of the barriers identified in access to training and provision of support. Research indicates that healthcare professionals face numerous barriers to treatment provision in various countries and settings [20,46], many of which could be addressed by the implementation of digital tools.

Despite high smoking prevalence, very few digital aids and programmes have been developed for Polish healthcare professionals or smokers, both in the general and patient populations. Moreover, very little is known about what digitally-based cessation support would be acceptable, relevant and feasible to be implemented in healthcare practice for both HCPs and patients in Poland.

\section{PROJECT STAR}

\section{PROJECT OBJECTIVES}

The overarching aim of the project is to expand the network of healthcare professionals involved in routinely offering evidence-based smoking cessation support, and thus to increase access to such support among patients who smoke.

The core objective of the project is to develop, evaluate and disseminate the internet-based STAR (Smoking Treatment Advisory Resource) Programme - a platform, which will serve as both a support tool and expert system 
for training, delivery of evidence-based treatment, data gathering, and networking for healthcare professionals (HCPs), and as a digital resource for patients who smoke. The project aims to address the gaps in training and provision of smoking cessation support in contexts where access to face-to-face training and specialist stop smoking services are limited, with a particular focus on Poland.

\section{PROJECT METHODS}

The project comprises of three main phases and follows guidelines on (i) complex intervention development [47], (ii) developing theory- and evidence-based interventions that are based on the COM-B model of behaviour, which proposes capability, opportunity and motivation as key influences on behaviour [48], as well as guidelines on (iii) development of person-centred [50] and digital healthcare interventions [50]. Phase 1 is devoted to the development of STAR, including formative research comprising literature reviews and synthesis, consultations with IT and cessation specialists, consultations and interviews with Polish HCPs and adult smokers from the general and patient populations, and adaptation of existing training resources created by HPF and the project partner - the National Centre for Smoking Cessation and Training (NCSCT) in the UK.

Phase 2 will involve mixed-methods evaluation of STAR including quantitative assessments of changes in key indicators from baseline to immediately post-training and at least 3-month follow-up to assess impact of STAR on clinical practice and advice on tobacco control. It is planned that up to $300 \mathrm{HCPs}$ will enrol into STAR. The project will be open to practicing HCPs in Poland, who represent a range of specialties in which the delivery of smoking cessation support could be particularly relevant and impactful. The primary target audience for the Project are secondary care physicians who are treating patients with tobacco-related diseases, i.e. cardiologists, pulmonologists, neurologists and oncologists. We also aim to engage and provide STAR to any HCPs with the capacity to offer cessation support to a wider population of patients: general practitioners, dentists, midwives, and nurses.

Finally, during Phase 3 the STAR Programme will be refined based on results from Phase 2 and promoted among a wider community of HCPs and patients, and the results disseminated.

\section{CONCLUSIONS}

It is expected that the project will result in the development of new, interactive, and acceptable tools for different HCPs in Poland, as well as their patients. Such resources could have tangible impact on tobacco control efforts by increasing the number of HCPs delivering evidence-based cessation support. Finally, the project will contribute to the research literature on digital smoking cessation programs and tools aiding clinicians. The proj- ect outcomes will help to inform future 'hybrid' programs involving digital tools supporting HCPs providing treatment for tobacco dependence, which are seen as an important element of smoking cessation programs in the future [37]. The findings will be especially informative for countries and settings where access to dedicated smoking cessation services is limited.

\section{ACKNOWLEDGEMENTS}

The project is conducted by Health Promotion Foundation (Fundacja "Promocja Zdrowia"), with the team members including Professor Witold A. Zatoński, Aleksandra Herbeć, Kinga Janik-Koncewicz, Mateusz Zatoński, Arlen Marciniak and Katarzyna Wijatkowska. The project is conducted in collaboration with Dr Andy McEwen at the National Centre for Smoking Cessation Training (NCSCT; United Kingdom), and Professor Robert West and his team at UCL Tobacco and Alcohol Research Group (UTARG; United Kingdom). The project is funded by Global Bridges at Mayo Clinic and Pfizer Independent Grants for Learning and Change Request for Proposals (RFP): EUROPEAN PROGRAM. The funding bodies have no influence over the project aims, methods and dissemination.

\section{DISCLOSURE}

Authors report no conflict of interest.

\section{References}

1. World Health Organization. WHO Framework Convention on Tobacco Control. World Health Organization, Geneva, 2003. Polish text of the Convention available in Dz.U. Nr 74/2006 poz. 487.

2. Peto R, Lopez AD, Boreham J, Thun M. Mortality from smoking in developed countries 1950-2000: United Kingdom 19502007. Oxford University Press, Oxford 2010.

3. Treating tobacco use and dependence: 2008 update: Clinical practice guideline. 2008. Available from: https://www.ncbi.nlm. nih.gov/books/NBK63952/ (accessed: 15 August 2017).

4. Stead L, Lancaster T. Combined pharmacotherapy and behavioural interventions for smoking cessation. J Evid Based Med 2012; 5: 242-242.

5. Zatonski W, Zatonski M. Cytisine versus nicotine for smoking cessation. N Engl J Med 2015; 372: 1072.

6. West R, Zatoński W, Cedzyńska M, et al. Placebo-controlled trial of cytisine for smoking cessation. N Engl J Med 2011; 365: 1193-1200.

7. Zatoński W, Cedzyńska M, et. al. An uncontrolled trial of cytisine (Tabex) for smoking cessation. Cochrane Database Syst Rev 2012; 10: CD008286.

8. Leaviss J, Sullivan W, Ren S, et al. What is the clinical effectiveness and cost-effectiveness of cytisine compared with varenicline for smoking cessation? A systematic review and economic evaluation. Health Technol Assess 2014; 18: 1-120.

9. Stead LF, Perera R, Bullen C, et al. Nicotine replacement therapy for smoking cessation. Cochrane Database Syst Rev 2012; 11: CD000146. 
10. Shahab L, Brose LS, West R. Novel delivery systems for nicotine replacement therapy as an aid to smoking cessation and for harm reduction: rationale, and evidence for advantages over existing systems. CNS Drugs 2013; 27: 1007-1019.

11. Cahill K, Stevens S, Perera R, Lancaster T. Pharmacological interventions for smoking cessation: an overview and network meta-analysis. Cochrane Database Syst Rev 2013; 31: CD009329.

12. Stead LF, Lancaster T. Behavioural interventions as adjuncts to pharmacotherapy for smoking cessation. Cochrane Database Syst Rev 2012; 12: CD009670.

13. Lancaster T, Stead LF. Individual behavioural counselling for smoking cessation. Cochrane Database Syst Rev 2005; 2 CD001292.

14. Aveyard P, Begh R, Parsons A, West R. Brief opportunistic smoking cessation interventions: a systematic review and meta-analysis to compare advice to quit and offer of assistance. Addiction 2012; 107: 1066-1073.

15. Glasgow RE, Whitlock EP, Eakin EG, Lichtenstein E. A brief smoking cessation intervention for women in low-income planned parenthood clinics. Am J Public Health 2000; 90: 786-789.

16. Pine-Abata H, McNeill A, Murray R, et al. A survey of tobacco dependence treatment services in 121 countries. Addiction 2013; 108: 1476-1484.

17. Kotz D, Fidler J, West R. Factors associated with the use of aids to cessation in English smokers. Addiction 2009; 104: 1403-1410.

18. Raupach T, West R, Brown J. The most "successful" method for failing to quit smoking is unassisted cessation. Nicotine Tob Res 2013; 15: 748-749.

19. Himelhoch S, Riddle J, Goldman HH. Barriers to implementing evidence-based smoking cessation practices in nine community mental health sites. Psychiatr Serv 2014; 65: 75-80.

20. Blumenthal DS. Barriers to the provision of smoking cessation services reported by clinicians in underserved communities. J Am Board Fom Med 2007; 20: 272-279.

21. Taha NA, Guat Tee O. Tobacco cessation through community pharmacies: Knowledge, attitudes, practices and perceived barriers among pharmacists in Penang. Health Educ J 2014; 74 681-690.

22. Ganz O, Fortuna G, Weinsier S, et al. Exploring smoking cessation attitudes, beliefs, and practices in occupational health nursing. Workplace Health Saf 2015; 63: 288-296.

23. Zatoński M, Zatoński W, Przewoźniak K, Jaworski M. The sig nificance and impact of the Polish Anti-tobacco Law. J Health Inequal 2016; 2: 32-35.

24. GATS Poland Collaborating Team. Global Adult Tobacco Survey (GATS) Poland 2009-2010. Ministry of Health, Warsaw 2010.

25. European Commission, Attitudes of Europeans towards Tobacco and Electronic Cigarettes. Available from: http://ec.europa. eu/commfrontoffice/publicopinion/archives/ebs/ebs_429_ en.pdf (accessed: 15 August 2017)

26. Zatonski W. Consensus on the diagnostics and treatment of tobacco dependence. Gazeta Lekarska 2008; 1-16.

27. Główny Inspektorat Sanitarny, Report on the program of limiting the health consequences of tobacco use in Poland in 2014. Available from: https://gis.gov.pl/images/sprawozdanie_ poznpt_2014.pdf (accessed: 15 August 2017).
28. Centre H.a.S.C.I., Statistics on NHS Stop Smoking Services in England. 1 April 2013 to 31 March 2014. Final Report. Available from: https://digital.nhs.uk/catalogue/PUB23213 (accessed: 15 August 2017).

29. Garg AX, Adhikari NK, McDonald H, et al. Effects of computerized clinical decision support systems on practitioner performance and patient outcomes: a systematic review. JAMA 2005; 293: 1223-1238.

30. Berlin A, Sorani M, Sim I. A taxonomic description of computer-based clinical decision support systems. J Biomed Inform 2006; 39: 656-667.

31. Naughton F, Jamison J, Boase S, et al. Randomized controlled trial to assess the short-term effectiveness of tailored web- and text-based facilitation of smoking cessation in primary care (iQuit in practice). Addiction 2014; 109: 1184-1193.

32. Kottke TE, Brad Rindal D, Rush WA, et al. Persistence of smoking-cessation decision support use in a dental practice. Am J Prev Med 2015; 48: 722-728.

33. Rindal DB, Rush WA, Schleyer TK, et al. Computer-assisted guidance for dental office tobacco-cessation counseling: a randomized controlled trial. Am J Prev Med 2013; 44: 260-264.

34. Vegesna A, Tran M, Angelaccio M, Arcona S. Remote patient monitoring via non-invasive digital technologies: A systematic review. Telemed J E-Health 2017; 23: 3-17.

35. Naughton F, Prevost AT, Gilbert H, Sutton S. Randomized controlled trial evaluation of a tailored leaflet and SMS text message self-help intervention for pregnant smokers (MiQuit). Nicotine Tob Res 2012; 14: 569-577.

36. Patrick K, Hekler EB, Estrin D, et al. The pace of technologic change: implications for digital health behavior intervention research. Am J Prev Med 2016; 51: 816-824.

37. Pulverman R, Yellowlees PM. Smart devices and a future of hybrid tobacco cessation programs. Telemed J E-Health 2014; 20: 241-245.

38. Curry SJ, Ludman EJ, McClure J. Self-administered treatment for smoking cessation. J Clin Psychol 2003; 59: 305-319.

39. Balhara YP, Verma R. A review of web based interventions for managing tobacco use. Indian J Psychol Med 2014; 36: 226-235.

40. Shahab L, McEwen A. Online support for smoking cessation: a systematic review of the literature. Addiction 2009; 104: 1792-1804.

41. Chen YF, Madan J, Welton N, et al. Effectiveness and cost-effectiveness of computer and other electronic aids for smoking cessation: a systematic review and network meta-analysis. Health Technol Assess 2012; 16: 1-205, iii-v.

42. Whittaker R, McRobbie H, Bullen C, et al. Mobile phonebased interventions for smoking cessation. Cochrane Database Syst Rev 2012; 11: CD006611.

43. Naughton F, Jamison J, Sutton S. Attitudes towards SMS text message smoking cessation support: a qualitative study of pregnant smokers. Health Educ Res 2013; 28: 911-922.

44. Herbec A, Beard E, Brown J, et al. The needs and preferences of pregnant smokers regarding tailored Internet-based smoking cessation interventions: a qualitative interview study. BMC Public Health 2014; 14: 1070.

45. West R. The clinical significance of "small" effects of smoking cessation treatments. Addiction 2007; 102: 506-509. 
46. Vogt F, Hall S, Marteau TM. General practitioners' and family physicians' negative beliefs and attitudes towards discussing smoking cessation with patients: a systematic review. Addiction 2005; 100: 1423-1431.

47. Campbell NC, Murray E, Darbyshire J, et al. Designing and evaluating complex interventions to improve health care. BMJ 2007; 334: 455-459.

48. Michie S, Atkins L, West R. The Behaviour Change Wheel: A guide to designing interventions. $1^{\text {st }} \mathrm{ed}$. Silverback Publishing, 2014.

49. Yardley L, Morrison L, Bradbury K, Muller I. The person-based approach to intervention development: application to digital health-related behavior change interventions. J Med Internet Res 2015; 17: e30.

50. Michie S, West W. A Guide to Development and Evaluation of Digital Behaviour Change Interventions in Healthcare. Silverback Publishing, 2016.

\section{AUTHORS' CONTRIBUTIONS}

$\mathrm{AH}$ prepared the project concept and drafted the publication. KJK contributed to article revision and edits. WAZ, AM and RW consulted on STAR project. All authors approved the final version of the article. 